\title{
Influence of Quality Counseling on Performance of Family Planning Programs in Kuresoi North Sub-County, Nakuru County, Kenya
}

\author{
Jenifer Wothaya Wambugu, Dorothy Ndunge Kyalo, John Mbugua, Regina Mutave \\ School of Open and Distance Learning, University of Nairobi, Nairobi, Kenya \\ Email address: \\ wothayaj@yahoo.com (J. W. Wambugu), wothayajen@gmail.com (J. W. Wambugu) \\ To cite this article: \\ Jenifer Wothaya Wambugu, Dorothy Ndunge Kyalo, John Mbugua, Regina Mutave. Influence of Quality Counseling on Performance of \\ Family Planning Programs in Kuresoi North Sub-County, Nakuru County, Kenya. American Journal of Applied Psychology. \\ Vol. 9, No. 4, 2020, pp. 66-76. doi: 10.11648/j.ajap.20200904.12
}

Received: May 5, 2020; Accepted: June 4, 2020; Published: June 17, 2020

\begin{abstract}
This study investigated quality counseling influence on performance of family planning programs in Kuresoi North Sub-County, Nakuru County, Kenya. The study was founded on the theory of constraint and adopted a pragmatism paradigm. It applied descriptive research method using mixed method approach to investigate the influence of quality counseling on performance of family planning program in Kuresoi North Sub-County, Nakuru County, Kenya. The target population in the study was women of reproductive age in 33,482 households distributed in the four Wards of Kuresoi North Sub-County and 19 health management leaders in-charge of all government health facilities offering family planning services in the Sub-County. A sample size of 400 of women of reproductive age and 19 nursing officers in-charge of government health facilities was utilized. The data collection tools used were questionnaire, interview guide, and observation checklist for women of reproductive age and the interview guide for the health facility managers. The research study adopted stratified sampling method. Qualitative data was analyzed according to themes and patterns and then summarizing the data and linking it to objectives and hypothesis. The study findings indicate that there is moderate quality counseling exhibited pertaining to family planning in the dispensaries and health centers located in Kuresoi North Sub-County. Further findings exhibited that there was a significant and strong positive individual correlation between quality counseling and performance of family planning program in Kuresoi North Sub-County. Finally, the study findings also exhibited that there is a significant positive relationship between quality counseling and performance of family planning program in Kuresoi North Sub-County and it predicted the performance of family planning programmes. in Kuresoi North Sub-County.
\end{abstract}

Keywords: Quality Counseling, Family Planning Program, Reproductive Age

\section{Introduction}

Family planning programs make a key starring role in prevention of maternal and infant mortality. Despite the benefits associated with family planning, many women continue to encounter unattained family planning needs leading to unwanted pregnancies and compromised health for women and children. A report by the World Health Organization (WHO) [1] indicated that globally, two hundred and fourteen million females of procreative age from underdeveloped nations would like to use a family planning method for child spacing but continue to face challenges and barriers to accessibility.
A quality family planning service should ensure adherence, persistent, and positive referral of individual users as well as contribute to the overall improvement of health indicators especially maternal as well as neonatal health [2].

Efficiency is a performance of family planning program dimension, which entails offering health care amenities in a technique that it is able to maximize the limited resource use and avoiding wastage. Accessibility is yet another performance of family planning program aspect, which comprises of offering health services that are opportune, physically reasonable, and offered in an atmosphere where knowledge, capacities and resources are suitable to health necessity and client counseling. Another performance of 
family planning program dimension identified was patientcentered which entails offering health care services, which considers individual or client predilections and goals, and the cultural setup of their societies. Another aspect is unbiassed, which is providing health care services that do not discriminate a person due to individual features like sex, race, culture, topographical setting, or financial standing. In addition, safety was considered as a performance of family planning program aspect. It entails providing health care services, which lessens jeopardies and damage to service consumers.

Achievement in programs related to family planning has been associated with key benefits to countries and the population. The major benefits as described by the report by WHO [1] are averting pregnancy-linked health dangers in women, dropping new-born mortality, supporting to avert HIV/AIDS, empowering individuals and improving education, as well as dropping adolescent pregnancies and decelerating population advance. Performance of programs related to contraceptives remains significant in attaining the United Nations Sustainable Development Goals. USAID through knowledge for health program revealed that there exists a gap in implementation of family planning worldwide.

Kenya made a great milestone in addressing quality in health by launching Kenya Quality Model of Health (KQMH) care [3], which provided a conceptual framework for offering holistic and scientific services through addressing a variety of structural quality matters with the key purpose of delivering health effects that are positive.

Counselling dimension in family planning is a health quality dimension that endeavours to deliver family planning services taking into account the predilections and ambitions of clients and the philosophies of their societies through organized counselling. This includes client satisfaction, client preference, and selection [4].

Counseling is an interactive relationship amongst a therapist and a customer or an assembly of customers with an intention of supporting a patient in addressing the health apprehensions of importance to them. The description outlines the role of the counsel as that of assisting clients to address their concerns. Counseling can be viewed as a corner stone to family planning programs [4].

Family planning counselling is the procedure of helping a client seeking contraceptive services from a trained health worker with an intention of making a well-versed and intended selections about the number of offspring and the spacing of the children that the family intends to raise by use of the most suitable family planning method. Health care workers play a significant part in counselling of clients for uptake of contraceptive services. Many health care providers have taken up counselling as part of their roles [4].

Owing to its significance and practicality, counseling is expansively developing a foundation for operative execution for health programs related to sexual and reproductive health. The significance of counseling is well recognized for its contribution in the change of behavior positively especially geared in the direction of seeking health care, and also contraceptives [4].

Despite the launch of the KQMH care document, there is no study conducted on the implementation of KQMH and the influence on performance of family planning program in Nakuru County. Family planning services are very critical services in preventive health especially at primary health care level. This study has utilized the healthcare quality dimensions of quality counseling in relation to performance of family planning program in Nakuru County, focusing on Kuresoi North Sub-County.

The remaining part of this paper is arranged as follows. Section two discusses about literature reviews. Section three deals with data and research methodology. The last two sections focus on empirical analysis and conclusions respectively.

\section{Literature Review}

Counseling of clients is an important component in family planning program since it helps the clients to make wellversed decision [4].

The health care providers in a family planning perspective include nurses, clinical officers, HIV counsellors, and community health volunteers. The more the health care providers have been involved with counselling on family planning, the more the quality of counselling is affected [5]. The research disclosed a reduction in the quality of counselling in Burkina Faso, Ethiopia, Kenya and Uganda due to involvement of informal practitioners like community health workers.

When a counsellor or a therapist has gone through an experience, it is usually very important to share an experience with clients for them to identify themselves with the situation. This can be referred to as Self-disclosure where a therapy uses her experience to help the others. A study by Sleater and Scheiner [6] supported the use of personal experience to help clients overcome some situations or to make decisions. The major intention of the research was to ascertain family planning excellence and its connection with contraceptive usage in government facilities in Burkina Faso, Ethiopia, Kenya, and Uganda. The indicators for counselling dimension in this study will be presence of a trained health care provider, client information on all available options, client knowledge on undesirable effects and ability of health care provider to use counselling process.

Counselling on reproductive health related issues should be based on trust. Building a trusting relationship need to be well cultivated by a therapist. This is in convergence with recommendation by Malcolm and Golsworthy [7] on the benefits of building a trusting relationship.

For clients to accept to use contraceptives services in African setup there is a necessity to carry out social mobilization to create awareness on facilities and the advantages of family planning to both men and women. This was the finding in a study by Shattuck, Wesson, Nsengiyumva, Kagabo, and Bristow [8] on accomplishment of family planning aiming at vasectomy acceptance among 
men. In the study, there was need to have demand creation through social behaviour and communication component to advocate the utilization of contraception for men especially the permanent method. The study further recommended the use of existing structures such as leadership at all levels and the change of the current family planning polices to include social culture and to address the gender issues. Performance of family planning program therefore requires all-inclusive of the key stakeholders and the users in all stages of implementation to factor quality of services.

There has been a notable decrease in the quality of counselling due to upsurge in the number of carders in health care provision offering family planning amenities including informal providers. This is convergence with a study conducted in selected countries. These countries were Ethiopia, Burkina Faso, Uganda and Kenya. The research was done by Fruhauf, Zimmerman, Kibira, Makumbi, Gichang, Shiferaw, Seme, Guiella, and Tsu [5] on calculating contraceptive excellence as well as its connection with contraceptive usage in municipal health care facilities in the four countries. In addition, the study indicated that quality of services and contraceptive use were compromised by an upsurge in informal providers offering contraceptive amenities. The study however needed to define the carders and counselling background of the informal family planning providers and compare the utilisation of family planning being provided by formal and informal providers.

Health care workers need to be empowered to be able to link their services with results. Linking counselling and the uptake of contraceptive has been a challenge in many settings. Numerous researches have established the relationship between the two. In a study that analysed 23 studies by Zapata, Tregear, Curtis, Tiller, Pazol, MautoneSmith, and Gavin [9] on impact of Contraceptive Counselling in Clinical Settings, the study established a robust positive association between counselling and uptake of contraceptives. The study explored the impact on studies carried out on different age groups to include adolescents, and adults and all indicated a positive impact on contraceptive performance.

Many programs have utilized peers to support adherence to treatment. This was informed by the notion of "expert patient" which was developed with emergence of conditions such as HIV/AIDs. It is believed that patients understand their body well, the treatment process and the outcomes. This was echoed by Boulet [10] in the study that assessed use of peer educators amongst patients with chronic respiratory conditions. The concept was considered to be very successfully but had a challenge of integrating the peer educators with the large medical care team. Use of contraceptives amongst young people could borrow the concept to help in clarifying rumours, myths, and misconceptions.

With counselling being a dynamic process, there has been efforts to identify the type of counselling that work well for clients and patients, different cases requires targeted counselling process [11]. A combination of strategies, could be employed for instance, use of a counsellor, and use of a peer counsellor. The most important outcome of counselling should be the ability of a client to manage the condition. This could be utilized in family planning where different strategies of counselling can be employed with an optimal goal of client ability to make long-term decisions appertaining recreation with an informed consent and ability to adhere to these decisions.

With an increase in population and reduced health workforce, many nations have been trying to initiate new innovative strategies of reaching clients without physical contacts. Telephone coaching was established in order to support patients with chronic illness on self-management. Dennis, Harris, Lloyd, Powell-Davies, Farugi, and Zwar [12] through a research found that use of coaching using telephones was associated with better wellbeing actions, selfefficiency as well as improved general health. Though telecoaching was utilized in counselling patients with chronic illness, it could be utilized in family planning where clients can be called for appointment reminders, and follow-up on how the family planning method was working. This can be explored in developing nations due to shortage of health workforce and barriers related to accessibility of well being services.

Many patients continue to depend on health workers to manage their health needs. It is important for clients and patients to be empowered to take health under their control. This would help them manage their health needs, expectations, seek timely health interventions, and adhere to treatment for better outcome. This was echoed by Boule, Boulay, Gauthier, Battisti, Chabot, Beauchesne, and Côté [13], who opined that empowering patients through health education could result to better health outcomes as demonstrated in a case study amongst asthmatic patients. Contraceptive programs should embrace the concept of patient education through counselling to be able to make informed decisions and manage their reproductive health goals.

Patients' personal views and perceptions are key in determining utilization of services including wellbeing services. Health care workers need to have that consideration in mind while making any decision regarding a client. Legar, Turcotte, Stacey, Ratt, Kryworuchko, and Graham [14] stated that different approaches need to be considered to share decisions with patients since they are likely to adhere to the actions in the decisions, they perceive best for them. This calls for health workers to always interrogate and explore patients' perceptions. Contraceptive utilization needs to utilize the concept for better uptake of commodities.

Many patients and clients never get an opportunity to participate in any decision regarding their health. Health professionals made decision that best favours a patient or client. They however do not involve the patients to understand the magnitude of failure to comply to the decisions. Better outcomes could be realized if clients and patients were involved in making their health decisions or if they were part of the decision-making [15]. Use of 
contraceptives has been associated with economic, social and health benefits among others. Women need to be educated on the benefits in order to make informed decisions.

Many studies have revealed the significant role that peer counsellors could play in the care of patients especially at the community level. If this concept is embraced, the hospitals could be decongested since patients can easily get information and literature from their peers. This was also echoed in a study by Cordier [16], which stated the important of empowering patients to do self-management of chronic illness. Patients need proper counselling in order to do selfcare. This could be utilized in reproductive health programs

Despite the fact young persons are a key target in offering family services, many organizations or institutions have not documented the impact of reproductive health counselling to the young persons and the update of reproductive health facilities including family planning [17]. The study endeavoured to find out if confidentiality in family planning services for young people impacted on uptake of services. The study however, indicated that absences of research investigating whether discretion in family planning amenities to young person's affects reproductive health results and recommended a vigorous research program considering the significance young people associate with confidentiality particularly regarding their reproductive health.

For effective counselling of young people, health care provider perspective is very important since it determines if the young people can take up the services. This was indicated in a study by William, Appiah, and Botchway [18] on customer and service provider perceptions on quality of care. The study further revealed that family planning services both client and benefactor perceptions to be extra effective. The study recommended for further research to scrutinize the effect of enhanced quality on benefactor practices, customer actions, and health consequences. The studies however failed to segregate the age of the young people utilising family planning services, which could be key in addressing the gaps. Targeted studies are required especially targeting counselling young people on reproductive age.

Client centred approach have been determined to influence client's uptake of family planning services. In convergence, with this, is a study carried out in Jordan, which considered client centred counselling as a key component and strategy towards achieving the government's goal of dropping its entire fertility rate to 2.1 by 2030 [19]. The current study seeks to explore the replicability of the same in African setting, which has shortage of human resource for health making it difficult to implement in such settings.

For clients to accept any family planning services, there is need to carry out a lot of social mobilization to create awareness on services and the benefits of family planning to both men and women. In convergence with this, Shattuck, Wesson, Nsengiyumva, Kagabo, and Bristow [8], studied on implementation of family planning targeting vasectomy uptake among men. In the study, there was need to have demand creation through social behaviour and communication component to advocate the use male family planning methods especially the permanent method. The study further recommended the use of indicated that there was need to change polices and consider social culture to address the gender issues. Implementation of family planning program therefore requires all-inclusive to be successful and involve the users in all stages of implementation.

\section{Data and Research Methodology}

This section profiles the research procedures that were applied to address the research objective. These included research model, research strategy, target populace, sample size, and sampling methods, research tools, data gathering methods, data analysis systems, ethical attention and operational description of variables. It also describes the procedures undertaken to guarantee the validity as well as the reliability of the investigation instruments. The section equally includes the ethical concerns. The section concludes with the description of variables.

\subsection{Research Paradigm}

This study was steered by pragmatisms paradigm since the study integrated quantitative and qualitative research strategies by use of mixed technique of data collection and examination. The fundamental hypothesis of the mixed study methodology is that blending numerical and non-numerical techniques offers a comprehensive knowledge of the investigation problem compared to applying only single kind of techniques [20] and [21]. This is in concurrence with discoveries from a study by Mitchell [22] who described dual case studies that utilized mixed study approaches and revealed that use of mixed study delivered both quantitative as well as qualitative perceptive which resulted to superlative data elucidation as well as the superlative understanding of the investigation phenomena.

Mixed approaches research provided additional thoughtful of the multifaceted phenomena that was likely to otherwise not be available through using single method only [23]. Pragmatism paradigm was carefully chosen as the most appropriate for this survey since the survey aimed to examine the influence of contraceptives supply on performance of family planning program in Kuresoi North Sub-County, Nakuru County, Kenya.

The choice of the paradigm was to accommodate the diverse approaches of data gathering as indicated by Morgan [24] that pragmatism is predominantly suitable for mixed methods. In addition, pragmatism permitted the investigator to be free of psychological and hands-on constrictions executed by the "involuntary optimal contradiction amid post positivism and constructivism [25]. It also enabled the investigator to be independent hence not obliged to a certain research method or technique [26].

\subsection{Research Design}

The study utilized the descriptive survey using mixed techniques research design. Mixed method is a procedure for 
steering research that encompasses gathering, scrutinizing and assimilating quantifiable statistics such as surveys and qualitative statistics such as interviews and observation guide [27]. The choice of mixed method was to offer a better consideration of the research problem. The method was selected considering that there had not been a study in Kuresoi North Sub-County testing the effect of quality counseling on any health program especially family planning. It was of paramount important to therefore use a method that would enable the investigator to continuously review the research question from diverse angles and elucidate unforeseen discoveries and/or probable contradictions.

Use of mixed method approach gave advantage to the study as described by Skiles, Cunningham, Inglis, Wilkes, Hatch, Bock, and Barden-O'Fallon [28] whereby, through use of the approach, the investigator was able to examine uniformity of outcomes obtained by various tools which included; household survey, interview guide, and observation checklist. It also offered data complementation by using both numerical and non-numerical statistics to evaluate overlapping but distinctive aspects of the research phenomenon.

\subsection{Target Population}

The target population in this study was 33,482 households in Kuresoi North Sub-County, Nakuru County. This number of households in Kuresoi North Sub-County was drawn from the Kenya health information system. The study also targeted the 19 nursing officers in-charge of all government health care facilities offering contraceptive services in Kuresoi North Sub-County.

This target population was useful in providing the required data in the topic under investigation, which was quality counselling and performance of family planning program in Kuresoi North Sub-County, Nakuru County, Kenya. The target population of 33,482 households was guided by the households mapped in Kuresoi North Sub-County as per the 2009 Census and 4\% estimated annual population growth as tabulated in the Kenya health information system 2019. The women of procreative age in Kuresoi North Sub-County was equally guided by 2019 Population Estimates revised for Kuresoi North Sub-County as populated in the Kenya Health Information system developed in 2019. This estimate of population and households is usually calculated guided by the population as per the census and the annual growth rate per Sub-County in relation to the proportion of each age cohort. Kuresoi North Sub-County has an estimated growth rate of $4 \%$ per year.

The health care facility in-charges comprised of all 19 officers of government health care facilities in Kuresoi North Sub-County. The women of procreative age were reached at the household level by trained community health volunteers. The estimated number of households in Kuresoi Sub-County were 33,482 which accounts $19.2 \%$ of the total population distributed in the four wards of the Sub-County. The inclusion of the health facility managers in this study was to enhance an understanding on quality counselling and performance of the family planning program.

The inclusion criterion for women of procreative age was the women within the procreative age cohort in a household that were eligible for collecting data from. The exclusion criteria were women of non-procreative age as per the operational definition irrespective of utilizing family planning services. The inclusion criteria for health care facility in-charges was only the nursing officers in-charge of all the government health facilities in Kuresoi North offering family planning services while the exclusion criteria were private health care facility nursing officers in-charge irrespective of offering family planning.

\subsection{Sample and Sampling Procedures}

Sample scope that was utilized for the survey was taken by applying Slovin's method designated by the populace size and the standard allowance error of 0.05 as specified in the equation below.

$$
\text { Sample size }(\mathrm{n})=\frac{N}{/\left(1+N e^{2}\right)}
$$

Where; $\mathrm{n}=$ number of samples, $\mathrm{N}=$ population scope, $\mathrm{e}=$ margin of index or error margin. The error margin employed in the study was $5 \%$ as the confidence interval utilized for social sciences is $95 \%$ and the consequent error margin is $5 \%$. Hence, the sample size obtained for the study was 400 respondents.

The sample was allocated in the four wards using the fisheries method for stratified random sampling procedure. The purpose of this method was to maximize sample survey precision from the calculated sample size. This is enumerated in Table 1.

The population that was being investigated was homogenous, the study adopted stratified random sampling technique. The definition is in convergence with description by Kamhawi, Underwood, Murad, and Jabre [19] who defined stratified random sampling as a process by which populace is segregated into subcategories known as "strata". Out of which every stratum, the same random sampling is applied in choosing for each-stratum sample. The overall each-stratum samples are thereafter joined to come up with the stratified random sample. It encompassed dividing the populace into standardised subdivisions and then getting a simple random sample in each subcategory.

Table 1. Sampling frame.

\begin{tabular}{ll}
\hline $\mathbf{N ~ N}$ & Number of stratum (SU1) in the population \\
\hline $\mathrm{M}_{\mathrm{i}}$ & Total of components (SU2) in stratum (SU1) i \\
$M o=\sum_{j=1}^{N} M i$ & Aggregate number of components (SU2) in the populace \\
$M=\frac{M o}{N}$ & Mean number of components (SU2) for every stratum (SU1). \\
\hline
\end{tabular}




\begin{tabular}{ll}
\hline $\mathbf{N ~ N}$ & Number of stratum (SU1) in the population \\
\hline$Y_{i j}$ & Value of the selected trait of component (SU2) in stratum (SU1) $\mathrm{i}$ \\
$Y j=\sum_{J=1}^{M j} Y i j$ & Aggregate value of the preferred attribute in stratum (SU1) i \\
$Y j=\frac{Y j}{M j}$ & Mean value of the distinctive $\mathrm{Y}$ in the components (SU2) of stratum (SU1) $\mathrm{i}$ \\
$Y=\sum_{J=1}^{N} Y j$ & Aggregate value of the distinctive $\mathrm{Y}$ in the populace \\
$Y=\frac{Y}{N}$ & Mean value of the distinctive $\mathrm{Y}$ for every stratum (SU1) \\
$Y=\frac{Y}{M o}=\frac{Y}{N M}=\frac{Y}{M}$ & Mean value of the trait $\mathrm{Y}$ for every component (SU2) \\
$Y=\sum_{j=1}^{N} \frac{Y j}{N}$ & Mean value of the feature $\mathrm{Y}$ for every component (SU2) if Mi= constant $=\mathrm{M}$ \\
\hline
\end{tabular}

\subsection{Data Collection Procedures}

The research assistants were guided by the Ward administrator, community health volunteer, the area chief, area assistant chief, and the village elder to identify a central point in each Ward, which was to be the initial point for sampling the households in each ward. The ward was further dived into four routes which informed the starting point. Each direction or route had equal number of questionnaires per the ward. To determine the starting point of data collection, the research assistant rolled a pen on the ground. The direction the sharp edge pointed was the initial route used to commence data collection. The research assistants further visited the first household and then skipped two households and visited every third household in the selected direction.

The research assistants ensured that they always started from the central starting point in the four routes selected. Upon getting to the household, the research assistants introduced her/himself, sought to know if the household had a woman of reproductive age, and if present, and sought permission from the household head or equivalent to administer the household questionnaire with assurance of confidentiality. For the households that did not have a woman of childbearing age, the research assistant moved to next household without skipping then continued with the pattern of skipping two households.

This study utilized a household questionnaire, key informant interview guide, and observation checklist for data collection. The survey tool for women of procreative age in the designate wards was a questionnaire. The key informant interview guide was utilized among the in-charges of health care facilities. Observation checklist was utilized to assess the nineteen health care facilities in Kuresoi North SubCounty. The choice of these instruments was directed by the type of data to be gathered, the dimensions and distribution of the population and also the goal of the research. The use of questionnaire in this study was carefully chosen since it allowed the questioner to gather a more deep and comprehensive information since the interviewer could selfcontrol the procedure henceforth searching additional by adding questions that aided to add additional information dissimilar in an observation method

The questionnaire and interview guide were tested in Molo Sub-County, Nakuru County, Kenya. The pilot test targeted 15 women of procreative age. The choice of Molo SubCounty in Nakuru county was because it was not a study site.
The two health facilities were randomly selected in Molo sub-county. The process of piloting was aimed at identifying whether women of reproductive age would understand the interrogations and instructions as well as whether the substance of questions was the similar for all respondents. For the household questionnaire, which had closed ended questions, piloting helped to check the sufficiency of response in the categories that were available. The responses from the participants was also expected to reveal presence of any inconsistencies in the questions within the questionnaire and ability of respondent to respond to all questions. The pilot study gave proper guidance on the tools. The tool collected the data which was intended hence they was no need of revising the tools.

\subsection{Research Instruments Validity and Reliability}

Inferences around the uses of the research apparatuses or instruments was validated. The validation was carried out to ensure that the research instruments had a suitable inference relevant to the purpose of the study and that the research instrument had a meaningful inference hence giving meaningful information using the instrument. The research instrument was tested to divulge the three categories of validity, which were; content-interrelated indication of validity, the criterion-interrelated indication of validity and the construct interrelated indication of validity. Utilization of experts in the area of reproductive health was done to help in assessing the subject matter validity. The tool was reviewed by the county health management team for any error. A small team that comprised of County Director of Strategic Planning, County Director of Quality Assurance and County reproductive health coordinator were tasked to review and give feedback on content. The review was followed by a presentation to the county health management team and later permit to collect data was given. The researcher put into consideration sentiments of raised by the Nakuru County Health Management Committee.

To ensure reliability of the research tools, they were exposed to testing to guarantee that the features of steadiness and equivalency were certain. The method used to measure reliability of the study tools was test re-test method. The interview guide was tested in two health facilities in Molo Sub-County targeting health facility in-charges while the questionnaire for the women of procreative age was tested in Kuresoi North Sub-County interviewing 20 women of procreative age at house level. The women of procreative age were visited in their respective households, explained to 
about the survey and upon giving consent, they were interviewed. They were given an appointment of one month when the researcher returned to the same households and interviewed the same women using the same questionnaire. The two-health facilities in-charge were interviewed utilizing the interview manual and the given an appointment of one month after which the same interview manual was utilized to interview them. The results of the two sets of were calculated for correlation using SPSS.

\subsection{Data Analysis Techniques}

This survey produced both quantitative and qualitative data to describe the influence of quality counseling on performance of family planning program. The filled questionnaires were obtained, coded, and edited for comprehensiveness and steadiness. The data was examined by applying descriptive and inferential statistics using the Statistical Package for Social Science (SPSS). This was utilized to give both descriptive and inferential statistics which enhanced examination of the hypothesis at the significance level of 0.05 and the confidence interval of $95 \%$.

Qualitative data was analyzed from the in-depth interviews and observation checklist and involved analyzing transcripts and identifying themes within that data. This also involved putting together themes that were alike from the text thus qualitative data was analyzed by checking data, developing codes, identifying themes and patterns, and then summarizing the data and linking them to objectives and hypothesis.

A simple linear regression analysis was carried out to analyze the influence of quality counseling on the performance of family planning program. The hypothesis was also analyzed using Pearson's Product Moment Correlation for interpretation of results. Correlation analysis was key in order to determine the association between the independent and dependent variables. Finally, the data was analyzed descriptive statistics for the quantitative analysis of data. The data was then be presented using frequency distribution tables for easier understanding.

\section{Empirical Analysis}

The empirical analysis section contains four parts that include; descriptive statistics, content analysis, correlation analysis, simple linear regression analysis, and discussion of empirical findings.

\subsection{Descriptive Statistics}

The study sought to determine the mean, standard error and standard deviation of quality counseling. This was analyzed using SPSS. There were ten questions distributed among the four indicators of the independent variable (quality counseling). The mean, standard error and standard deviation was analyzed as per as the results in the in Table 2 below.

Table 2. Quality counselling descriptive statistics.

\begin{tabular}{lllll}
\hline & N & Mean & & Std. Deviation \\
\cline { 2 - 5 } & Statistic & Statistic & Std. Error & Statistic \\
\hline Counseling Dimension & 400 & 30.48 & 0.486 & 9.729 \\
Valid N (listwise) & 400 & & & \\
\hline
\end{tabular}

The results displayed a mean of 30.48 , standard error of 0.486 , and standard deviation of 9.729 . The interpretation is about $68 \%$ of the sample population (assuming a normal distribution) at one standard deviation was between (30.48 $0.486)=29.994$ and $(30.48+0.486)=30.966$, which has an average of 30.48 . This indicated that the sample population tended to be neutral on quality of counseling in the health facilities they were seeking family planning services. The views of the sample population gave the same views with the total population which was between $30.48-9.729=20.751$ and $30.48+9.729=40.209$ with average of 30.48 .

The study also sought to measure the mean and standard deviation of performance of family planning program. Table 3 shows the results.

Table 3. Performance of family planning program descriptive statistics.

\begin{tabular}{llll}
\hline & N & Mean & Std. Deviation \\
\hline & Statistic & Statistic & Std. Error \\
\hline Performance & 400 & 36.43 & 0.368 \\
Valid N (listwise) & 400 & & Statistic \\
\hline
\end{tabular}

The results display a mean of 36.43 , SE of 0.368 and SD of 7.357 . This implies that $68 \%$ of the sample population at one standard deviation is between $(36.43-0.368)=36.0621$ and $(36.43+0.368)=36.798$, which has an average of 36.43 . This indicated that the sample population tended to agree on the performance of family planning program. The views of the sample population gave the same views with the total population, which was between $36.43-7.357=29.073$ and
$36.43+7.357=43.787$ with average of 36.43 .

\subsection{Content Analysis}

Nursing officers' in-charge of government health facilities were interviewed on availability and adequacy of family planning rooms. $100 \%$ indicated the facilities had family planning counseling rooms. $89.5 \%$ indicated that the counseling room was adequate, well equipped, spacious well 
ventilated and could accommodate client and her partner, while $10.5 \%$ indicated that even though they had a family planning counseling room, it was not adequate for counseling and some procedures. The further indicated that some procedures like insertion of Intra-uterine Contraceptive Devices (IUCD) were done in maternity.

Nursing officers were interviewed on how they got feedback from clients on family planning and how the clients felt. $47.5 \%$ indicated that they probed clients during the return visit to get feedback on the progress. $31.5 \%$ indicated that they got regular feedback from community health volunteers. $10.5 \%$ indicated that they conducted exit interviews with support from development partners such as Afya Uzazi. $10.5 \%$ stated that they got feedback through suggestion box. There is need for the community strategy to be enhanced considering that $31.5 \%$ of the facility in-charges relied on feedback from community health volunteers.

A question on how the health care facilities ensured male involvement in contraceptive use was asked during the interview with nursing officers in-charge of health facilities. $52.6 \%$ were enhancing male involvement by counseling clients to initiate a discussion on accompanying her to the clinic. They relied on client's ability to convince their partners to accompany them. $21.1 \%$ relied on health education give to all clients and patients every morning where men are encouraged to accompany their women to the health facilities. $15.8 \%$ enhanced male involvement by giving services to the couple's first. $10.5 \%$ enhanced male involvement by providing male services during family planning outreaches such as having a male desk, issuing condoms and vasectomy.

Mode of counseling the health facilities were using was determined during the interview with the nursing officers in-charge of health facilities. $63.2 \%$ indicated that they carried out-group counseling to all women awaiting family planning, followed by demonstration on how each method works and the procedure required. After group counseling, women would then get into the family planning room one by one having chosen the method after counseling and the health worker recaps on that method and issues the same. $36.8 \%$ indicated that they carried out individual counseling.

While group counseling saves time and is subject to women making decision as a result of peer influence, though it was not part of the household survey, it was noted that some women relied on their peers in decision making. At least five women reported to be using two hormonal family planning methods. They were on one method but when they missed their periods, upon consulting their friends, they tried another method. This indicated that counseling left some question unanswered raising the issue of quality. The nursing officers in-charged further indicated that they took between 5 to 10 minutes to counsel clients on family planning and that they followed World Health Organization (WHO) protocols while counseling clients.

\subsection{Correlation Analysis}

The study sought to establish the influence of quality counseling on performance of family planning program in Kuresoi North Sub-County, Nakuru County, Kenya. Quality counseling as an independent variable was guided by four indicators which were; leadership, health care providers skills and level of training, adherence to guidelines, and report and documentation. Table 4 shows the correlation.

Table 4. Correlations analysis.

\begin{tabular}{llll}
\hline & & $\begin{array}{l}\text { Counseling } \\
\text { Dimension }\end{array}$ & Performance \\
\hline Counseling & Pearson Correlation & 1 & $.711^{* *}$ \\
Dimension & Sig. (2-tailed) & & 0 \\
& $\mathrm{~N}$ & 400 & 400 \\
& Pearson Correlation & $.711^{* *}$ & 1 \\
Performance & Sig. (2-tailed) & 0 & 400 \\
& $\mathrm{~N}$ & 400 & 400 \\
\hline
\end{tabular}

**. Correlation is significant at the 0.01 level (2-tailed).

The study identified a strong positive correlation of 0.711 between quality of counseling dimension and performance of family planning program in Kuresoi North Sub-County. The correlation was also significant because the significance value obtained in the study was less than the critical value $(\mathrm{P}=0.00<0.05)$. Therefore, there is a significance relationship between quality of counseling and performance of family planning program.

\subsection{Simple Linear Regression Analysis}

The study sought to test the fitness of the model on relationships between quality counseling and performance of family planning programs. The study also sought to test hypothesis that there is no significant relationship between quality counseling and performance of family planning program. Finally, the study sought to measure the strength of the relationship between quality counseling and performance of family planning program. Tables 5 shows the results of the model.

Table 5. Simple linear regression analysis.

\begin{tabular}{llllll}
\hline Model & R & & R Square & & Adjusted R Square \\
\hline 1 & $.711^{\mathrm{a}}$ & & 0.506 & 0.505 & Std. Error of the Estimate \\
\hline & & & & & \\
\hline Model & & Sum of Squares & Df & Mean Square & F \\
\hline \multirow{3}{*}{1} & Regression & 10927.117 & 1 & 10927.117 & 407.555 \\
& Residual & 10670.923 & 398 & 26.811 & \\
& Total & 21598.04 & 399 & & \\
\hline
\end{tabular}




\begin{tabular}{lllllll}
\hline \multirow{2}{*}{ Model } & \multicolumn{2}{c}{ Unstandardized Coefficients } & \multicolumn{2}{c}{$\begin{array}{l}\text { Standardized } \\
\text { Coefficients }\end{array}$} & \multirow{2}{*}{ T } & \\
\cline { 3 - 6 } & & B & Std. Error & Beta & \\
\hline \multirow{2}{*}{1} & (Constant) & 20.037 & 0.852 & & 23.511 & 0 \\
& Counseling Dimension & 0.538 & 0.027 & 0.711 & 20.188 & 0 \\
\hline
\end{tabular}

a. Dependent Variable: Performance

b. Predictors: (Constant), Counseling Dimension

The results showed that $\mathrm{R}$ Square value was 0.505 . Thus, quality counseling predicts $50.5 \%$ of performance of the family planning program in Kuresoi North Sub-County, Nakuru County, Kenya.

The result also indicated that significance value obtained in the analysis of variance is 0.00 , which is less than the critical of 0.05 . Thus, the null hypothesis that quality counseling does not predict performance of family planning program is rejected. Hence, the model of quality counseling predicting performance is therefore fit.

The result indicated that significance value obtained from the model coefficients is 0.00 , which is less than the critical value of 0.05 . Thus, quality counseling significantly affects performance, the null hypothesis that quality counseling does not significantly affect performance of family planning program is rejected. The following model is thus developed;

$$
\mathrm{Y}=20.037+0.538 \mathrm{X}
$$

This implies that when one improves quality counselling by one unit, there is an increase in performance of family planning program by 0.538 units.

\subsection{Discussion of Findings}

The study findings displayed that there was a significant and strong positive correlation between quality counseling and performance of family planning program in Kuresoi North Sub-County. The study findings also exhibited that there is a significant positive relationship between quality counseling and performance of family planning program in Kuresoi North Sub-County. The study further exhibited that quality counseling predicted and described to a large extent the performance of family planning.

The current study findings are congruent to a study by Zapata, Tregear, Curtis, Tiller, Pazol, Mautone-Smith, and Gavin [9] on impact of Contraceptive Counselling in Clinical Settings. The study established a robust positive association between counselling and uptake of contraceptives. The study explored the impact on studies carried out on different age groups to include adolescents, and adults and all indicated a positive impact on contraceptive performance.

The study findings are parallel to the findings of the study conducted by Boulet [10], which assessed use of peer educators amongst patients with chronic respiratory conditions. The concept was considered to be very successfully but had a challenge of integrating the peer educators with the large medical care team and use of contraceptives amongst young people could borrow the concept to help in clarifying rumours myths and misconceptions.

The study findings are also in tandem with the study by Law and School [11], which discovered that different cases requires targeted counselling process. The study enumerated that a combination of strategies could be employed for instance, use of a counsellor, and use of a peer counsellor and the most important outcome of counselling should be the ability of a client to manage the condition. Thus, this could be utilized in family planning where different strategies of counselling can be employed with an optimal goal of client ability to make long-term decisions appertaining recreation with an informed consent and ability to adhere to these decisions.

The current study findings are in convergence to a study conducted by Dennis, Harris, Lloyd, Powell-Davies, Farugi, and Zwar [12], which found out that use of coaching using telephones was associated with better wellbeing actions, selfefficiency as well as improved general health. The study stressed that the tele coaching was utilized in counselling patients with chronic illness, it could be utilized in family planning where clients can be called for appointment reminders, and follow-up on how the family planning method was working. Thus, this can be explored in developing nations due to shortage of health workforce and barriers related to accessibility of well being services.

The current study findings echo the study conducted by Boule, Boulay, Gauthier, Battisti, Chabot, Beauchesne, and Côté [13], which outlined that empowering patients through health education could result to better health outcomes as demonstrated by a case study it conducted amongst asthmatic patients. It further enumerated that contraceptive programs should embrace the concept of patient education through counselling to be able to make informed decisions and manage their reproductive health goals.

The current study findings are also similar to the findings of the study conducted by Legar, Turcotte, Stacey, Ratt, Kryworuchko, and Graham [14], which stated that different approaches need to be considered to share decisions with patients since they are likely to adhere to the actions in the decisions they perceive best for them. The study reiterated for health workers to always interrogate and explore patients' perceptions and that contraceptive utilization needs to utilize the concept for better uptake of commodities.

The current study findings are convergent with the study done by Wilson, Strub, and Buist [15], which indicated that better outcomes could be realized if clients and patients were involved in making their health decisions or if they were part of the decision-making. Additionally, the use of contraceptives has been associated with economic, social, and health benefits among others and women need to be 
educated on the benefits in order to make informed decisions.

The study findings are in tandem with the study conducted by Cordier [16], which stated the importance of empowering patients to do self-management of chronic illness and that patients need proper counselling in order to do self-care, this could be utilized in reproductive health programs.

The current study findings are in tandem with a study carried out in Jordan that considered client centred counselling as a key component and strategy towards achieving the government of Jordan goal of dropping its entire fertility rate to 2.1 by 2030 [19].

Finally, the current study findings are in convergence with a study conducted by Shattuck, Wesson, Nsengiyumva, Kagabo, and Bristow [8], which focused on implementation of family planning targeting vasectomy uptake among men. The study specified that there was need to have demand creation through social behaviour and communication component to advocate the use male family planning methods especially the permanent method. The study further recommended the use of indicated that there was need to change polices and consider social culture to address the gender issues. The conclusion of the study was that implementation of family planning program therefore requires all-inclusive to be successful and involve the users in all stages of implementation.

\section{Conclusions}

The study concluded that there was a significant and strong positive correlation between quality counseling and performance of family planning program in Kuresoi North Sub-County.

The study also concluded that there is a significant positive relationship between quality counseling and performance of family planning program in Kuresoi North Sub-County. The study finally concluded that quality counseling predicted and described to a large extent the performance of family planning.

Thus, recommendations can be made to the health regulatory authorities and health facilities to increase their counseling services in order to increase the performance of family planning programs. In order to increase quality counseling, the health care providers should; have cordial relationships with their clients, enquire about clients medical history, ask clients about their contraceptive goals, advise clients about the contraceptive methods available and discuss reasons that some methods may not be appropriate to them, demonstrate how to use the methods and explain how to deal with possible problems related to its use, use any visual aid to help explain the method, and enquire about partner's attitude towards use of family planning

The current study conclusions are congruent to the conclusions of the study by Zapata, Tregear, Curtis, Tiller, Pazol, Mautone-Smith, and Gavin [9] on impact of Contraceptive Counselling in Clinical Settings. The study concluded that a robust positive association between counselling and uptake of contraceptives. The study explored the impact on studies carried out on different age groups to include adolescents, and adults and all indicated a positive impact on contraceptive performance.

The study conclusions are parallel to the conclusions of the study conducted by Boulet [10], which assessed use of peer educators amongst patients with chronic respiratory conditions. The concept was considered to be very successfully but had a challenge of integrating the peer educators with the large medical care team and use of contraceptives amongst young people could borrow the concept to help in clarifying rumours myths and misconceptions.

The study conclusions are also in tandem with the conclusions of a 2010 study, which concluded that different cases requires targeted counselling process. The study enumerated that a combination of strategies could be employed for instance, use of a counsellor, and use of a peer counsellor and the most important outcome of counselling should be the ability of a client to manage the condition. Thus, this could be utilized in family planning where different strategies of counselling can be employed with an optimal goal of client ability to make long-term decisions appertaining recreation with an informed consent and ability to adhere to these decisions [11].

\section{References}

[1] Family planning/Contraception Key facts, World Health Organization, (2018).

[2] S. Cohen and W. Yu. Rockville, "The Concentration and persistence in the level of health expenditures over time: Estimates for the U.S. population 2009-2010," MD: Agency for Healthcare Research and Quality; Nov, 2012.

[3] Implementation Guideline for Kenya Quality Model of Health (KQMH) Care, Ministry of Medical services and Ministry of Public Health and sanitation, 2012.

[4] M. J. Saka, L. A. Yahaya, \& A. O. Saka, "Counselling and client provider-interactions as related to family planning services in Nigeria," Journal of Education and Practice, Vol 3, No. 5, pp. 16-25, 2012.

[5] T. Fruhauf, I. Zimmerman, S. P. Kibira, F. Makumbi, P. Gichang, S. Shiferaw, A. Seme, G. Guiella, \& A. Tsu, (2018). Measuring family planning quality and its link with contraceptive use in public facilities in Burkina Faso, Ethiopia, Kenya and Uganda. Health Policy and Planning, https:orordoi.orgor10.1093orheapolorczy058.

[6] A. M. Sleater, \& J. Scheiner, "Impact of the therapist's 'use of self'," The European Journal of Counselling Psychology, pp. 2195-7614, 2017.

[7] C. Malcolm, \& R. Golsworthy, "Working relationally with clients who have experienced abuse: Exploring counselling psychologists' experiences using IPA,” The European Journal of Counselling Psychology, pp. 2195-7614, 2019.

[8] D. Shattuck, J. Wesson, T. Nsengiyumva, L. Kagabo, \& H. Bristow "Who choses vasectomy in Rwanda? Survey data from couples who chose vasectomy contraception," Vol. 89, No. 6, pp. 564-71, 23 Dec 2016. 
[9] L. B. Zapata, S. J. Tregear, K. M. Curtis, M. Tiller, K. Pazol, N. Mautone-Smith, \& L. E. Gavin, "Impact of contraceptive counseling in clinical settings: A systematic review," American Journal of Preventive Medicine, Vol. 49, No. 2, pp. S31-S45, 2015.

[10] L. P. Boulet, "The expert patient and chronic respiratory diseases," Canadian Respiratory Journal, Vol 10, pp. 11 - 55, 2016.

[11] S. Lawn, \& A. School, "Patient education and counselling," Patient Educ Couns, Vol. 10. No. 6, pp. 205 -211, 2010.

[12] S. Dennis, M. Harris, J. Lloyd, G. Powell-Davies, N. Farugi, \& N. Zwar, (2011). Telephone coaching models to support chronic disease management in multi-morbid and vulnerable populations. An Evidence Check rapid review brokered by the Sax Institute for the NSW Ministry of Health. www.saxinstitute.org.au.

[13] L. P. Boule, M. E. Boulay, G. Gauthier, L. Battisti, V. Chabot, M. F. Beauchesne, \& P. Côté, "Benefits of an asthma education program provided at primary care sites on asthma outcomes," Respiratory Medicine, Vol. 109, No. 8, pp. 991$1000,2015$.

[14] F. Legar, S. Turcotte, D. Stacey, S. Ratt, J. Kryworuchko, \& I. D. Graham, "Patients' perceptions of sharing in decisions: A systematic review of interventions to enhance shared decision making in routine clinical practice," The Patient-Patient Centred Outcomes Research, Vol. 5, No. 1, pp. 1-19, 2012.

[15] S. R. Wilson, P. Strub, \& A. S. Buist, "Shared treatment decision making improves adherence and outcomes in poorly controlled asthma," American Journal of Respiratory and Critical Care Medicine, Vol. 181, No. 6, pp. 566-577, 2010.

[16] J. F. Cordier, "The expert patient: towards a novel definition," European Respiratory Journal. Vol. 44, No. 4, pp. 853-857, 2014.

[17] A. W. Brittain, J. R. Williams, L. B. Zapata, S. B. Moskosky, \& T. S. Weik, "Confidentiality in family planning services for young people: A systematic review," American Journal of Preventive Medicine, Vol. 49, No. 20 1, pp. S85-S92, 2015.
[18] O. William, E. E. Appiah, \& E. Botchway, "Assessment of customer expectation and perception of service quality delivery in Ghana commercial banks," Journal of Humanity, Vol. 4, No. 1, pp. 81-91, 2016.

[19] C. Kamhawi, C. Underwood, H. Murad, \& B. Jabre, "Clientcantered counselling improves client satisfaction with family planning visits: Evidence from Irbid, Jordan," Global Health: Science and Practice, Vol. 1, No. 2, pp. 180-192, Aug 2013.

[20] J. W. Creswell, Research Design: Qualitative, Quantitative, and Mixed Methods Approaches, 4th ed, 2014.

[21] J. F. Molina-Azorin, "Mixed methods research: An opportunity to improve our studies and our research skills," European Journal of Management and Business Economics, vol 25, pp 37-38, 2016.

[22] A. Mitchell, "A review of the mixed methods, pragmatism and abduction techniques," The Electronic Journal of Business Research Methods, vol 16, pp 103-116, 2018.

[23] J. W. Creswell, and V. L Plano-Clark, Designing and Conducting Mixed Methods Research, 2nd ed., Thousand Oaks, CA: Sage Publications, Inc, 2018.

[24] D. L. Morgan, pragmatism as a paradigm for social research, Qualitative Inquiry, vol 20, no 8, pp 1045-1053, 2014.

[25] C. Robson, Real World Research, Oxford, UK: Blackwell, 1993.

[26] J. Morse, and L. Niehaus, Mixed Method Design: Principles and Procedures, Walnut Creek, CA: Left Coast Press, 2010.

[27] T. D. Nguyen, M. Shih, D. Srivastava, S. Tirthapura, and B. $\mathrm{Xu}$, "Stratified Random Sampling from Streaming and Stored Data," Electrical and Computer Engineering Conference Papers, Posters and Presentations, 2019.

[28] M. Skiles, M. Cunningham, A. Inglis, B. Wilkes, B. Hatch, A. Bock, \& J. Barden-O'Fallon, "The effect of access to contraceptive services on injectable use and demand for family planning in Malawi," International Perspectives on Sexual and Reproductive Health, Vol 41, No. 1, pp. 20-30, 2015. 